\title{
Next Generation Nuclear Plant Structures, Systems, and Components Safety Classification White Paper
}

The INL is a

U.S. Department of Energy National Laboratory

operated by

Battelle Energy Alliance

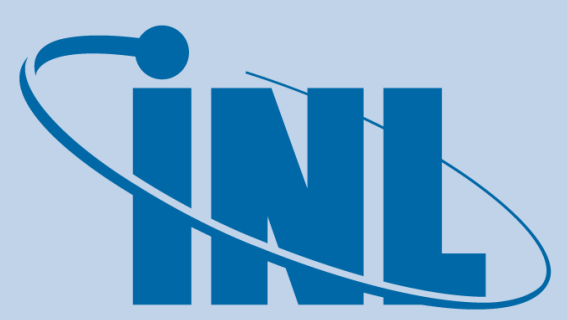

Idaho National Laboratory

September 2010

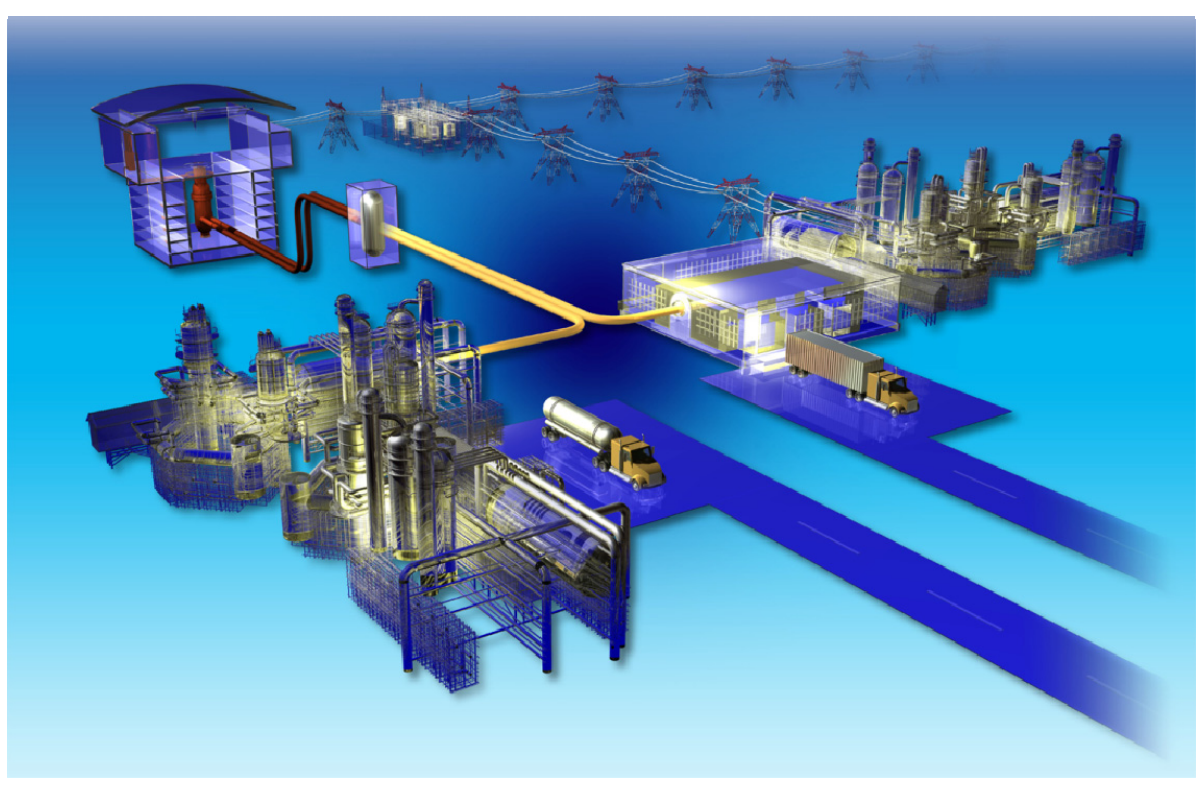




\section{DISCLAIMER}

This information was prepared as an account of work sponsored by an agency of the U.S. Government. Neither the U.S. Government nor any agency thereof, nor any of their employees, makes any warranty, expressed or implied, or assumes any legal liability or responsibility for the accuracy, completeness, or usefulness, of any information, apparatus, product, or process disclosed, or represents that its use would not infringe privately owned rights. References herein to any specific commercial product, process, or service by trade name, trade mark, manufacturer, or otherwise, does not necessarily constitute or imply its endorsement, recommendation, or favoring by the U.S. Government or any agency thereof. The views and opinions of authors expressed herein do not necessarily state or reflect those of the U.S. Government or any agency thereof. 
INL/EXT-10-19509

\section{Next Generation Nuclear Plant Structures, Systems, and Components Safety Classification White Paper}

September 2010

Idaho National Laboratory

Next Generation Nuclear Plant Project

Idaho Falls, Idaho 83415

Prepared for the

U.S. Department of Energy

Office of Nuclear Energy

Under DOE Idaho Operations Office

Contract DE-AC07-05ID14517 
This page is intentionally left blank. 
Next Generation Nuclear Plant Project

\section{Next Generation Nuclear Plant Structures, Systems, and Components Safety Classification White Paper}

INL/EXT-10-19509

September 2010

Approved by:
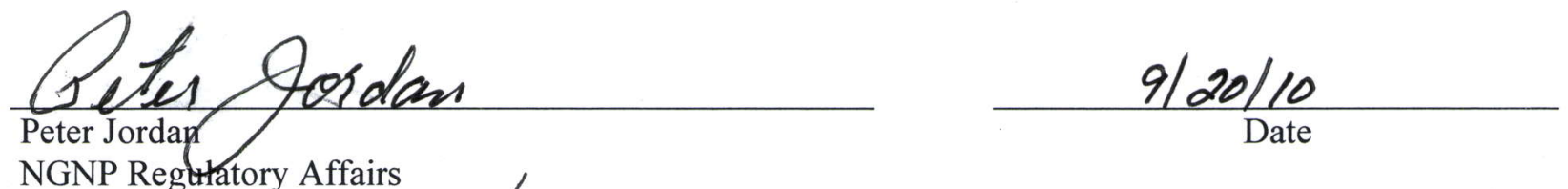

NGNP Regtthatory Affairs
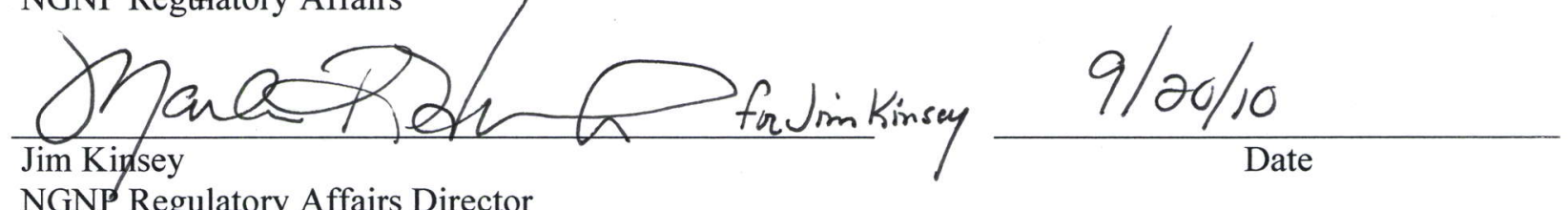

NGNP Regulatory Affairs Director
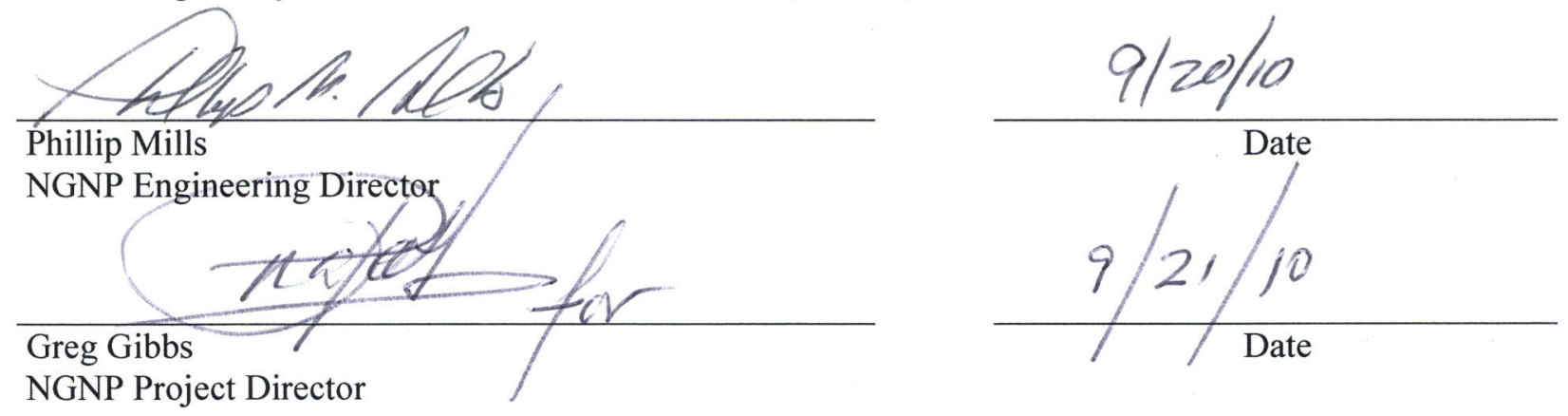
This page is intentionally left blank. 


\section{ABSTRACT}

This white paper outlines the relevant regulatory policy and guidance for a risk-informed, performance-based approach for establishing the safety classification of Structures, Systems, and Components (SSCs) for the Next Generation Nuclear Plant (NGNP) and sets forth certain facts for review and discussion to facilitate an effective submittal leading to an NGNP Combined License application under 10 CFR 52.

This paper (1) documents the approach that will be used to classify SSCs for the NGNP in accordance with their safety significance in conjunction with the principles of defense-in-depth and (2) identifies the specific questions proposed for discussions with the Nuclear Regulatory Commission. Defense-in-depth is a safety philosophy in which multiple lines of defense and conservative design and evaluation methods are applied to ensure the safety of the public. Based upon the selected licensing basis events and considering defense-in-depth attributes, the plant's SSCs are evaluated for the safety significant role they may play in preventing or mitigating the radiological consequence of such events in order to classify which SSCs are safety-related. The NGNP safety classification approach results in the classification of SSCs as SafetyRelated, Non-Safety-Related with Special Treatment, or Non-SafetyRelated.

The risk-informed, performance-based licensing approach proposed for NGNP includes the definition of Top Level Regulatory Criteria, as discussed in the companion white paper on Licensing Basis Event Selection. A previously submitted white paper on Defense-in-Depth Approach also addresses how the Top Level Regulatory Criteria are to be met during licensing basis events.

The information in this paper is intended to serve as the basis for interactions with the Nuclear Regulatory Commission staff. The NGNP project wishes to obtain comments on the adequacy of the planned SSC classification approach and feedback on a number of issues that have the potential to significantly impact the effort and schedule to prepare a Combined License application for NGNP. 
This page is intentionally left blank. 


\section{CONTENTS}

ABSTRACT

ACRONYMS

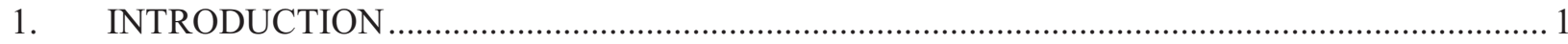

1.1 Purpose

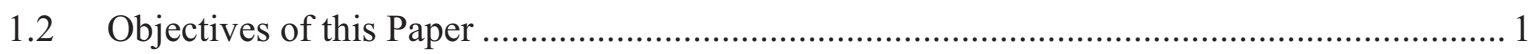

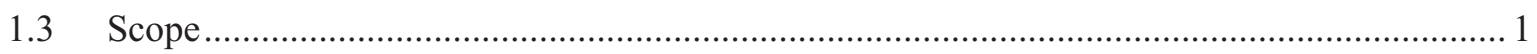

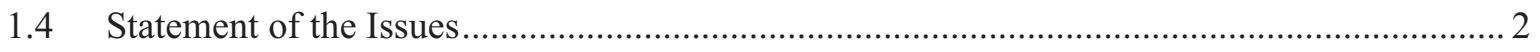

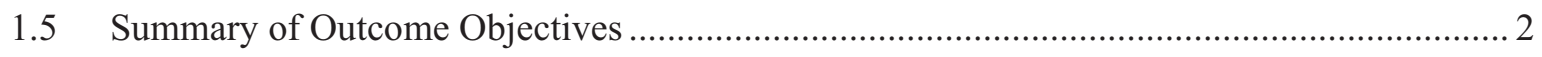

1.6 Relationship to Other NGNP Topics/Papers ....................................................................... 3

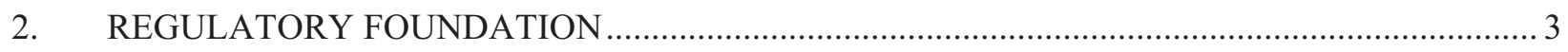

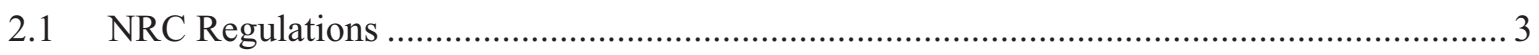

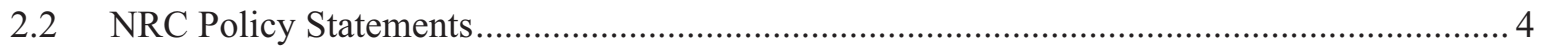

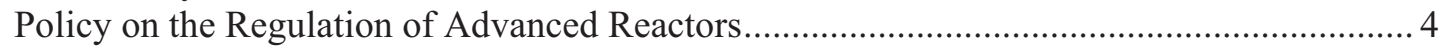

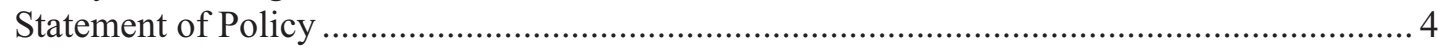

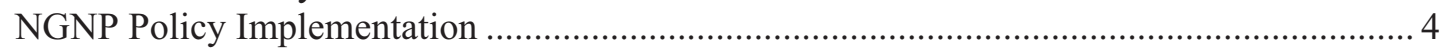

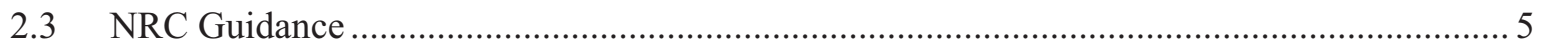

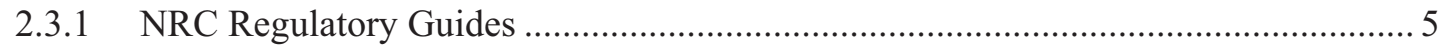

2.3.2 SECY-10-0034, "Potential Policy, Licensing, and Key Technical Issues for ............ 7

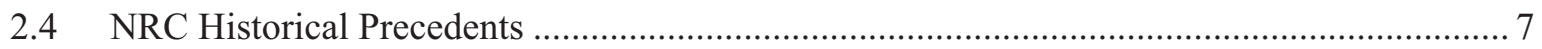

2.4.1 PBMR Responses to NRC Requests for Additional Information .............................. 9

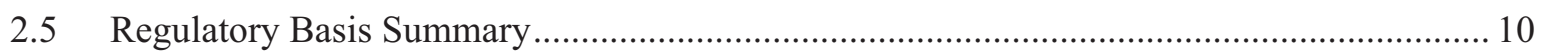

3. NGNP APPROACH TO STRUCTURES, SYSTEMS, and COMPONENTS SAFETY

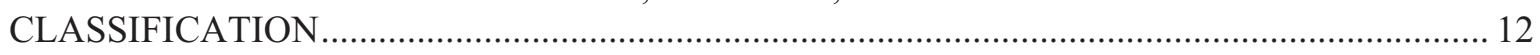

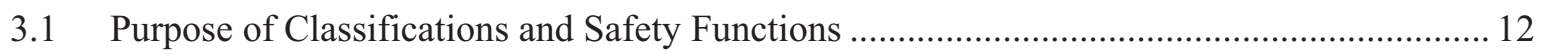

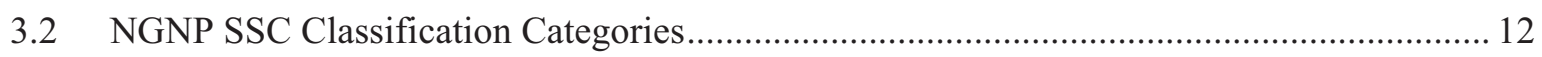

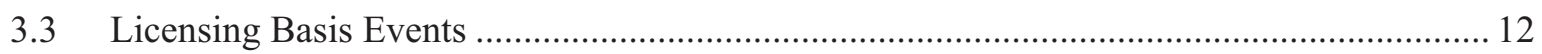

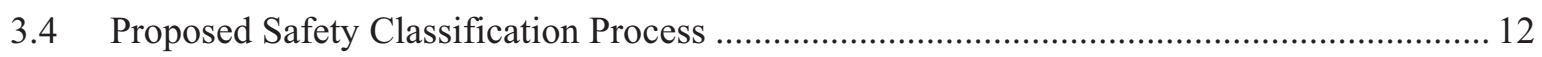

3.4.1 Basis for Risk Informing the Criteria for Safety Classification ................................ 13

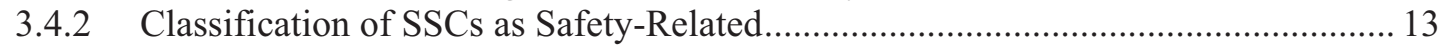

3.4.3 SSCs Classified as Non-Safety-Related with Special Treatment............................... 14

3.5 Example NGNP Safety Classifications for SSCs Identified via Risk Informed

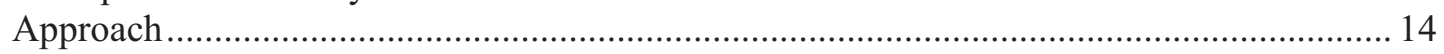

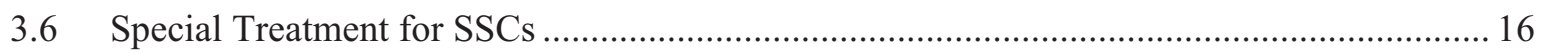

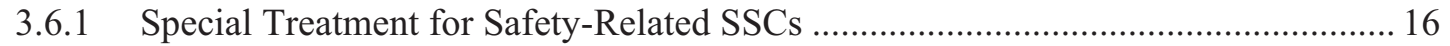

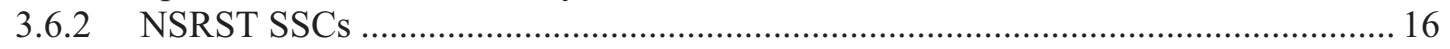

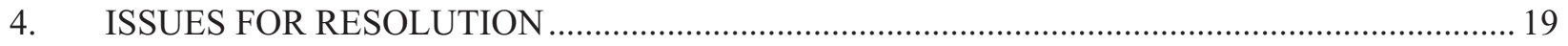

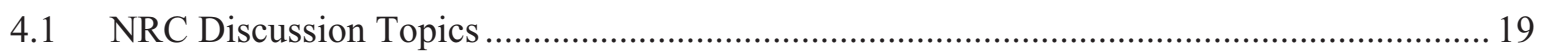

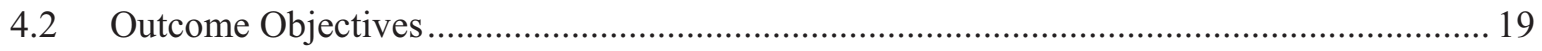




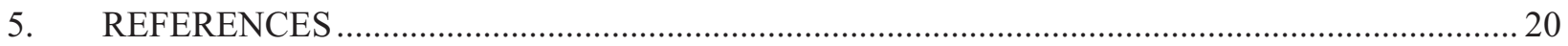

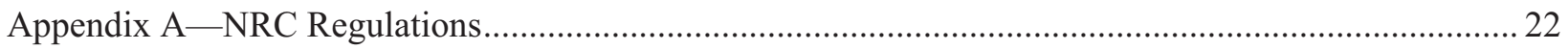

Table

Table 1 Elements of special treatment for safety-related and non-safety-related with special ........18 treatment SSCs

Figure

Figure 1 Impact of safety classified SSCs in prevention and mitigation of LBEs...................15 


\section{ACRONYMS}

AOO anticipated operational occurrences

ASME American Society of Mechanical Engineers

ATWS anticipated transients without scram

BDBE beyond design basis event

$\mathrm{CDF} \quad$ core damage frequency

CFR Code of Federal Regulations

COL combined license

DBA design basis accident

DBE design basis event

DID defense-in-depth

DOE Department of Energy

EAB exclusion area boundary

GDC general design criteria

HTGR high temperature gas-cooled reactor

LBE licensing basis event

LERF large early release frequency

LWR light water reactor

MHTGR modular high temperature gas-cooled reactor

NGNP next generation nuclear plant

NRC Nuclear Regulatory Commission

NSRST non-safety-related with special treatment

PBMR pebble bed modular reactor

PIUS process inherent ultimate safety

PRA probabilistic risk assessment

PRISM power reactor innovative small module

RAI request for additional information

RISC risk informed safety class

RG regulatory guide

RTNSS regulatory treatment of non-safety systems

SBO station blackout

SR safety related

SRP standard review plan

SSC structures, systems, and components 
TLRC top level regulatory criteria 


\section{Next Generation Nuclear Plant Structures, Systems, and Components Safety Classification White Paper}

\section{INTRODUCTION}

\subsection{Purpose}

This paper reviews the regulatory philosophy of Structures, Systems, and Components (SSCs) safety classification, defines the SSC safety classification methodology as appropriate for advanced reactor designs based on high temperature gas-cooled reactor technology (HTGR), and explains how this safety philosophy is achieved in the HTGR designs.

The risk-informed, performance-based licensing approach proposed for the Next Generation Nuclear Plant (NGNP) includes the definition of Top Level Regulatory Criteria (TLRC), as discussed in the companion white paper on Licensing Basis Event (LBE) Selection ${ }^{1}$ (Sections 2.3 and 3.3.3), that provide frequency and dose limits for LBEs. In this respect, the TLRC determines what must be met for licensing approval. The selection of the LBEs answers the question of when the TLRC are to be met. Additional elements of the NGNP licensing approach, such as defense in depth (DID), answer the questions of how and how well the TLRC are to be met. This white paper describes one of these latter elements: a riskinformed approach for the safety classification of NGNP SSCs. A previously submitted white paper, "NGNP Defense in Depth Approach," also addresses how the TLRC are to be met during LBEs. This DID philosophy recognizes that complete reliance for safety cannot be placed on any single element of the design, maintenance, or operation of a nuclear power plant. ${ }^{3}$ This defense-in-depth approach is mandated to define and select licensing basis events and plant features and the subsequent classification of SSCs to prevent or mitigate the consequences of postulated accidents.

\subsection{Objectives of this Paper}

The objectives of this paper are to:

- Summarize the regulatory requirements, guidance, and precedents that apply to SSC safety classification in general, and specifically, to advanced HTGR designs, including the NGNP design (Section 2).

- Develop HTGR-specific safety classification. Compare this classification with the classification typically used by the Nuclear Regulatory Commission (NRC) (Section 3.2).

- Describe the methodology for achieving the various aspects of SSC safety classification (Sections 3.2 and 3.3).

- Describe how the NGNP project SSC safety classification approach aligns with NRC expectations for greater use of risk-informed licensing practices (Sections 3.4 and 3.5).

- Describe a method for regulatory acceptance that demonstrates the adequacy and sufficiency of the SSC safety classification approach (Refer to Section 3.4).

\subsection{Scope}

This paper reviews the regulatory philosophy of SSC safety classification, defines the SSC safety classification methodologies as applicable to advanced reactor designs based on HTGR technology, and explains how this safety philosophy is achieved in the NGNP design. 


\subsection{Statement of the Issues}

The issues addressed in this white paper are framed in terms of answering the following questions regarding the safety classification of SSCs to support NGNP licensing:

- What is the role of safety classification of SSCs in the risk-informed, performance-based licensing approach for NGNP?

- What is an appropriate, systematic, and reproducible approach for safety classification of SSCs in a risk-informed, performance-based licensing approach?

- What are appropriate safety class categories for SSCs?

- How are deterministic approaches used and integrated into the safety classification process?

- How are risk-informed, performance-based approaches used and integrated into the safety classification and special treatment processes?

- What is the approach for assigning special treatment to assure the required degree of reliability and capability for SSCs classified as safety-related?

- What is the approach for assigning special treatment to assure the required degree of reliability and capability for SSCs classified as non-safety-related with special treatment?

The regulation and policy foundation for deriving this list of issues is developed in Section 2 of this white paper. The NGNP approach to safety classification of SSCs is outlined in Section 3. Section 4 defines the issues identified in the review of the regulatory foundation and in the technical development of the SSC approach, and provides NGNP's proposed resolution of these issues.

\subsection{Summary of Outcome Objectives}

The objective of this paper (and the follow-up interactions) is to obtain NRC agreement on the list of issues for the safety classification of SSCs to support NGNP licensing as well as agreement on the approach to resolving these issues. Specifically, NGNP would like the NRC to concur with the following statements; or provide an alternative set of statements with which they concur:

1. The NGNP risk-informed, performance-based approach to safety classification and special treatment that blends the strengths of deterministic engineering judgment and probabilistic methods, as recommended in SECY-03-0047 and SECY-10-0034, is acceptable. In accordance with Standard Review Plan (SRP) 3.2.2, "System Quality Group Classification," this is an optional approach provided by the process defined by 10 CFR $\$ 50.69 .^{7}$ The more traditional approach utilizes the guidance provided by Regulatory Guide (RG) $1.26^{8}$ and includes the definitions of 10 CFR $\$ 50.2^{7}$ (as applicable to HTGR design concept). The process described herein implements key aspects of both 10 CFR $\$ 50.69^{7}$ and $\S 50.2 .^{7}$

2. The use of safety classification categories developed from the provisions of $10 \mathrm{CFR} \$ 50.69,{ }^{7}$ and the bases for SSC classification in each category described below are acceptable:

\section{- $\quad$ Safety-Related (SR):}

- SSCs relied on to perform required safety functions to prevent or mitigate the consequences of design basis events (DBE) to comply with the TLRC

- SSCs relied on to perform required safety functions to prevent the frequency of beyond design basis events (BDBE) with consequences greater than the 10 CFR $\$ 50.34^{7}$ dose limits from increasing into the DBE region. 
- $\quad$ Non-Safety-Related with Special Treatment (NSRST):

- SSCs are relied on to perform functions to mitigate the consequences of anticipated operational occurrences (AOO) to comply with the TLRC

- SSCs are relied on to perform functions to prevent the frequency of DBEs with consequences greater than the 10 CFR $20^{9}$ offsite dose limits from increasing into the AOO region.

- Non-Safety-Related:

- All other SSCs (with no special treatment required).

Special treatment requirements are identified for SR and NSRT SSCs to assure the SSC capability and reliability in performing functions consistent with the TLRC and regulatory dose limits. Refer to Table 1.

\subsection{Relationship to Other NGNP Topics/Papers}

This paper on the safety classification of SSCs is linked to the previously submitted DID white paper, as noted above. In addition, it relies on input from the NGNP white paper on LBE selection for purposes of defining the frequency and consequences of DBEs for determining accident prevention and mitigation features of the plant.

Inherent in the NGNP safety design and licensing approach is the development and quantification of mechanistic source terms for the spectrum of LBEs. The white paper on licensing basis event selection ${ }^{1}$ provides a graphic representation of the relationship of individual NGNP white papers and is shown in Figure 1 of that white paper.

\section{REGULATORY FOUNDATION}

\subsection{NRC Regulations}

The NGNP Project has adopted the 10 CFR 52, Subpart C, Construction and Operating License (COL) application process, as recommended in the Report to Congress, ${ }^{7}$ as the foundation for the NGNP licensing strategy. This approach is judged to be the most expedient means of obtaining regulatory approval based on HTGR technology as applied to the NGNP Project.

As provided by $10 \mathrm{CFR} \S 52.81,{ }^{26} \mathrm{COL}$ applications will be reviewed by the NRC for compliance with the standards set out in 10 CFR $20,{ }^{9} 50,{ }^{7}$ and its appendixes, $51,{ }^{25} 73,{ }^{27}$ and $100 .{ }^{10}$ For classification of SSCs, various requirements of 10 CFR $20,{ }^{9} 50,{ }^{7}$ and $100^{10}$ apply but may, in some instances, require adjustment to be adaptable to HTGR technology. The pertinent aspects of these regulations for safety classification are more fully described in Appendix A.

- 10 CFR 20, Standards for Protection Against Radiation. ${ }^{9}$ The regulations promulgated under 10 CFR 20 establish standards for protection against ionizing radiation resulting from activities conducted under licenses issued by the NRC.

- 10 CFR 50, Domestic Licensing of Production and Utilization Facilities. ${ }^{7}$ The regulations promulgated under 10 CFR 50 provide the framework and requirements for licensing and production facilities. Although these regulations were developed for specific application to LWR technologies, they contain certain precepts and principles generally adaptable to HTGR technology.

SSCs for LWRs are primarily classified into one of two categories: 1) safety-related or 2) non-safety-related. 10 CFR $\$ 50.2^{7}$ defines safety-related SSCs as: 
...those structures, systems and components that are relied upon to remain functional during and following design basis events to assure:

(1) The integrity of the reactor coolant pressure boundary;

(2) The capability to shut down the reactor and maintain it in a safe shutdown condition; or

(3) The capability to prevent or mitigate the consequences of accidents which could result in potential offsite exposures comparable to the applicable guideline exposures set forth in $\S 50.34(\mathrm{a})(1)$ or $\S 100.11$ of this chapter, as applicable. ${ }^{7}$

NRC has other requirements for classifications for SSCs that relate to the safety basis of plant design and operation. These include requirements and supporting guidance that pertain to selected non-safety-related SSCs in LWRs that may be applicable. For example, fire protection SSCs are subject to requirements in $10 \mathrm{CFR} \S 50.48 ;^{7}$ certain equipment needed to mitigate anticipated transients without scram (ATWS) and station black out (SBO) events are subject to the requirements in $10 \mathrm{CFR} \S 50.62^{7}$ and $\$ 50.63,{ }^{7}$ respectively; and radwaste systems are subject to requirements in the LWR general design criteria (GDC) in Appendix A to 10 CFR $50 .^{7}$ This white paper does not address these ancillary classifications, but rather is limited solely to safety classification.

An alternate safety classification structure described in 10 CFR $\$ 50.69$ "Risk-informed categorization and treatment of structures, systems and components for nuclear power reactors,", defines safety significance categories for SSCs based on combinations of safety classification and risk significance as determined in a PRA.

This alternative regulatory framework is further discussed in Section 2.3 under RG 1.201. ${ }^{11}$

- 10 CFR 100, Reactor Site Criteria ${ }^{10}$

- $\quad 10$ CFR $\S 100.21(\mathrm{c})(2),{ }^{10}$ Non-Seismic Site Criteria, requires that the dose consequences of postulated accidents shall meet the criteria set forth in $\S 50.34(\mathrm{a})(1){ }^{7}$

\subsection{NRC Policy Statements}

\section{Policy on the Regulation of Advanced Reactors}

\section{Statement of Policy}

On October 14, 2008, the NRC published its revised policy regarding its expectations for the regulation of advanced reactors. ${ }^{12}$ For advanced reactor designs like the HTGR, the NRC expects at least the same degree of protection of the environment, public health and safety, and common defense and security that is required for current generation LWRs. In addition, NRC expects that advanced reactors will provide enhanced margins of safety or use simplified, inherent, passive, or other innovative means to accomplish their safety and security functions.

\section{NGNP Policy Implementation}

The HTGR design concept to provide protection of the environment, public health and safety, and common defense and security is to utilize simplified safety systems, plant features that minimize the potential for severe accidents, and a DID philosophy to maintain multiple barriers against radiation release. Both more traditional design features and innovative features, which include the use of passive means to prevent and mitigate design basis events (DBEs), will be evaluated for their risk significance for 
classification as safety class or non-safety class but with special treatment in accordance with 10 CFR $50.69^{7}$ through application of LBE selection and PRA techniques.

\subsection{NRC Guidance}

The U.S. NRC has promulgated 10 CFR $50.69^{7}$ to permit power reactor license holders and applicants to implement an alternative regulatory framework with respect to "special treatment," where special treatment refers to those requirements that provide increased assurance beyond normal industrial practices that SSCs perform their design-basis functions. Implementing guidance is presented in R.G. 1.201, "Guidelines for Categorizing Structures, Systems, and Components in Nuclear Power Plants According to Their Safety Significance," Revision 1, ${ }^{11}$ and Standard Review Plan (SRP) 3.2.2, "System Quality Group Classification," Revision 2. ${ }^{6}$ Under this framework, licensee holders and applicants using a risk-informed process for categorizing SSCs according to their safety significance can remove SSCs of low safety significance from the scope of certain identified special treatment requirements. However, SRP 3.2.2 ${ }^{6}$ does not include criteria for reviewing a risk-informed categorization approach. Further discussion of special treatment requirements is provided in SECY-10-0034. ${ }^{5}$

As explained more fully in Section 3, the NGNP approach to safety classification and special treatment of SSCs includes an alternate category as provided by 10 CFR $\S 50.69^{7}$ and RG 1.201 . $^{11}$

SECY $-03-0047^{4}$ recommends the use of a probabilistic approach for SSC safety classification.

The following discussion elaborates more fully on the regulatory guidance that is applicable or adaptable to HTGR technology, given that the existing body of regulatory guidance was developed based upon LWR design, analysis, and technology.

\subsubsection{NRC Regulatory Guides}

Over the years, NRC has issued numerous Regulatory Guides (RGs) addressing a variety of issues and design considerations. The RG series provide guidance to licensees and applicants on implementing specific parts of the NRC's regulations, techniques used by the NRC staff in evaluating specific problems or postulated accidents, and data needed by the staff in its review of applications for permits and licenses. Division 1 RGs apply to power reactors. While RGs were developed for application to LWRs, the body of RGs that relate to various aspects of SSC safety classification are sufficiently technology neutral as to also apply or be highly adaptable to HTGR design since they largely deal with qualitative safety criteria. However, there are some criteria that may require reevaluation for application to HTGR technology. These criteria are anticipated to be identified in a forthcoming NGNP white paper on Regulatory Gap Analysis.

\subsubsection{RG 1.26, "Quality Group Classifications and Standards for Water-, Steam-, and Radioactive-Waste-Containing Components of Nuclear Power Plants",}

General Design Criterion 1, "Quality Standards and Records," as set forth in Appendix A, "General Design Criteria for Nuclear Power Plants," in 10 CFR Part 50, "Licensing of Production and Utilization Facilities,"7 requires that SSCs important to safety are designed, fabricated, erected, and tested to quality standards commensurate with the importance of the safety functions to be performed. Under 10 CFR $\$ 50.55 \mathrm{a}$, "Codes and Standards,"7 certain systems and components of boiling- and pressurized-watercooled nuclear power reactors must be designed, fabricated, erected, and tested in accordance with the standards for Class 1, 2, and 3 components given in Section III, "Nuclear Power Plant Components," of the American Society of Mechanical Engineers (ASME) Boiler and Pressure Vessel Code (ASME III) ${ }^{13}$ or equivalent quality standards. This guide describes a quality classification system related to specified national standards that may be used to determine quality standards acceptable to the staff of the NRC for 
satisfying General Design Criterion 1 for other LWR safety-related components containing water, steam, or radioactive material in light-water-cooled nuclear power plants.

\section{NGNP Implementation}

Some components/materials in HTGR design do not have specific ASME code requirements developed at this time. NGNP anticipates conformance with ASME code requirements that exist today which are adaptable to HTGR design. NGNP also expects to conform to future code requirements, such as ASME Section III, Division 5, being developed for specific application to HTGR technology as discussed in "NGNP High Temperature Materials White Paper."

\subsubsection{RG 1.201, Guidelines for Categorizing Structures, Systems, and Components in Nuclear Power Plants According to Their Safety Significance ${ }^{11}$}

This regulatory guide describes a method that the NRC staff considers acceptable for use in complying with the Commission's requirements in 10 CFR $\$ 50.69^{7}$ with respect to the categorization of SSCs that are considered in risk-informing special treatment requirements. Special treatment refers to those requirements that provide increased assurance beyond normal industrial practices that SSCs perform their design-basis functions. Under this framework, licensees using a risk-informed process for categorizing SSCs according to their safety significance can remove SSCs of low safety significance from the scope of certain identified special treatment requirements. Specifically, this process determines the safety significance of SSCs and categorizes them into one of four risk-informed safety class (RISC) categories.

1. RISC-1 SSCs are safety-related SSCs that the risk-informed categorization process determines to be significant contributors to plant safety. Licensees must continue to ensure that RISC-1 SSCs perform their safety-significant functions consistent with the categorization process, including those safetysignificant functions that go beyond the functions defined as safety-related for which credit is taken in the categorization process.

2. RISC-2 SSCs are those that are defined as non-safety related, although the risk-informed categorization process determines that they are significant contributors to plant safety on an individual basis. The NRC staff recognizes that some RISC-2 SSCs may not have existing special treatment requirements. As a result, the focus for RISC-2 SSCs is on the safety-significant functions for which credit is taken in the categorization process.

3. RISC-3 SSCs are those that are defined as safety-related, although the risk-informed categorization process determines that they are not significant contributors to plant safety. Special treatment requirements are removed for RISC-3 SSCs and replaced with high-level requirements. These highlevel requirements are intended to provide sufficient regulatory treatment, such that these SSCs are still expected to perform their safety-related functions under design-basis conditions, albeit at a reduced level of assurance compared to the current special treatment requirements. However, 10 CFR $\$ 50.69^{7}$ does not allow these RISC-3 SSCs to lose their functional capability or be removed from the facility.

4. RISC-4 SSCs are those that are defined as non-safety related, and that the risk-informed categorization process determines are not significant contributors to plant safety. 10 CFR $\$ 50.69^{7}$ does not impose alternative treatment requirements for these RISC-4 SSCs. However, as with the RISC-3 SSCs, changes to the design bases of RISC-4 SSCs must be made in accordance with current applicable design change control requirements (if any), such as those set forth in 10 CFR $\$ 50.59 .^{7}$

This regulation provides for relaxation of specific special treatment requirements defined in the GDC of 10 CFR Part 50 for plants licensed under 10 CFR Part $50^{7}$ and for design certifications under 10 CFR Part 52. ${ }^{26}$ In effect, this regulation provides a way to "back-fit" risk insights into the traditional approach for safety classification by first performing a traditional safety classification according to 10 CFR $\$ 50.2{ }^{7}$ then performing a PRA, and expanding the two categories of safety class and non-safety class in terms of 
the above four safety significance categories. In addition, SECY $-03-0047^{5}$ recommends allowing the use of a probabilistic approach for the safety classification of SSCs.

\section{NGNP Implementation}

NGNP anticipates utilizing the guidance provided in Regulatory Guide $1.201^{11}$ for complying with the NRC's requirements in 10 CFR $50.69^{7}$ to determine the safety significance of SSCs and place them into the appropriate RISC categories as described in Section 1.5 of this white paper. The safety significance of SSCs is determined by using an integrated decision-making process, which incorporates both traditional deterministic engineering and risk insights. The safety functions of SSCs include both the design-basis functions (derived from the safety-related definition) and functions credited for preventing or mitigating severe accidents. Treatment requirements are then commensurately applied for the categorized SSCs to maintain their functionality. This approach is further discussed in Section 3.0.

\subsubsection{SECY-10-0034, "Potential Policy, Licensing, and Key Technical Issues for Small Modular Nuclear Reactor Designs"}

SECY-10-0034, issued March 28, 2010, summarizes the NRC's position on a number of advanced reactor policy issues including classification of SSCs for small modular reactors (SMRs) in general and to the HTGR proposed by NGNP. During its reviews of recent LWR design and license applications, the NRC staff has used deterministic judgment, complemented by insights from the design-specific PRA, to review SSCs relied on to prevent or mitigate safety-significant licensing-basis events. In conducting its reviews, the staff verified that safety margins were adequate to ensure the integrity and performance of safety-significant SSCs using a conservative analysis or a best-estimate analysis with consideration of uncertainties. The NRC staff expects to apply this approach to most of the advanced reactor design reviews. If necessary, special treatment requirements would be established to ensure the required performance capability and reliability of the safety-significant SSCs, using deterministic engineering judgment, complemented by insights and information from the design-specific PRA. The Department of Energy (DOE) and NRC stated that they planned to use this approach to classify the SSCs for the NGNP in the August 2008 Licensing Strategy Report to Congress. ${ }^{25}$

\subsection{NRC Historical Precedents}

In the late 1980s and early 1990s, the NRC conducted a pre-application review of the Modular HighTemperature Gas-Cooled Reactor (MHTGR) at the request of DOE. DOE proposed to classify the TRISO fuel for the MHTGR as safety-related, but not the reactor coolant pressure boundary or the containment. ${ }^{15}$ In addition, DOE proposed to use only the third of the three criteria in 10 CFR $\$ 50.2^{7}$ (i.e., SSCs needed to mitigate accident doses comparable to those in $10 \mathrm{CFR} \S 50.34^{7}$ ) for the classification of safety-related MHTGR SSCs and not the other two criteria (i.e., reactor coolant pressure boundary and SSCs needed for safe shutdown). This approach was adopted because of the inherent safety characteristics of the fuel as compared to LWR fuel design.

NRC addressed this position in SECY-93-092, Issues Pertaining to the Advanced Reactor (PRISM, MHTGR, and PIUS) and CANDU 3 Designs and their Relationship to Current Regulatory Requirements (April 8, 1993), Enclosure 1, page 28. ${ }^{16}$ NRC stated:

The NRC LWR safety classification criteria are based on the fundamental regulatory standard to require defense-in-depth for a reactor design and to require safety-related SSCs to separately protect the three barriers to potential releases of fission product radioactivity to the public: the fuel, the reactor coolant pressure boundary, and the containment. This approach by definition requires that safety-related SSCs be identified 
to protect more than just one of the traditional barriers, e.g., more than just the fuel barrier to radionuclide transport.

This conclusion was repeated when NRC published the results of its MHTGR review in NUREG1338, Pre-application Safety Evaluation Report for the Modular High-Temperature Gas-Cooled Reactor. ${ }^{17}$ In Sections 4.2.5 and 5.2.7 of NUREG-1338, NRC stated that it would apply the LWR criteria for safety-related SSCs to the MHTGR, and it concluded that DOE's proposed classification approach did not satisfy the NRC's regulations governing the classification of safety-related SSCs. However, NRC also stated that it would consider further justification from DOE for reducing the design, installation, and maintenance requirements of the staff-identified safety-related SSCs for the MHTGR ${ }^{17}$ during the design approval (which was never issued). NRC also stated that it would apply the regulatory treatment of nonsafety systems (RTNSS) to non-safety-related SSCs in the MHTGR.

In 2001 to 2002, the NRC staff conducted a pre-application review of the pebble bed modular reactor (PBMR) design at the request of Exelon. In a letter to Exelon dated March 26, 2002, ${ }^{18}$ the NRC staff provided its assessment of the licensing approach proposed by Exelon, including the TLRC. With respect to classification of SSCs, the NRC staff stated:

In its licensing approach, Exelon proposes that an appropriate set of regulatory design requirements for treatment of safety-related SSCs be developed for each DBE [design basis event] on a case-by-case basis, and that risk-informed special treatment then be applied to the corresponding SSCs. The approach proposed by Exelon is a novel approach that has not been previously considered by the staff in its risk-informed activities. Because Exelon's approach proposes to use frequencies and doseconsequences rather than CDF [core damage frequency] and LERF [large early release frequency] as risk metrics, it is not directly comparable with the risk-informed options currently being developed by the staff for risk-informing Part 50 regulations. The special treatment requirements for classified SSCs will be developed based on the required function for each DBE. The approach proposed by Exelon has the potential to impose special treatment requirements on equipment at the component level. Establishing requirements at the component level would present difficulties in documenting the design criteria for each component and establishing a consistent application of special treatment requirements on a system level. Also, while Exelon has stated that it does not anticipate the need for special treatment of SSCs solely for the purpose of preventing or mitigating EPBEs [emergency planning basis events], the staff emphasizes that SSCs relied on to avoid exceeding TLRC [top level regulatory criteria], or to keep the frequencies of similar event sequences within the acceptable range (e.g., within the AOO [anticipated operational occurrence], DBE, or EPBE range) should be classified as safety-related. The staff also expects that the treatment applied to safety-related SSCs should consider the limiting environment under which the SSCs must be available to perform their safetyrelated design function. In addition, Exelon's discussion of monitoring the performance of SSCs does not specifically address the monitoring of safety-related SSCs to identify unexpected equipment performance or to ensure that the regulatory design requirements are being met. Because Exelon proposes to use PRA [probabilistic risk assessment] to classify components as safety-related, there must be sufficient monitoring to ensure the validity of the SSC reliability and availability assumptions that are used in the engineering evaluation (i.e., PRA) underlying Exelon's safety-related classifications. The staff notes that the term safety-related may not be directly applicable to the PBMR concept, and that a more appropriate term may have to be developed. The staff will continue to pursue these issues with Exelon during the staff's pre-application review. (Enclosure, pp. 15-16). ${ }^{18}$ 
Following the Exelon review, the NRC staff provided the Commission a status report on the policy implications from licensing non-LWR designs and the staff's plans for seeking Commission guidance on resolving the issues. Three overarching policy issues and four policy issues of a more specific nature were discussed in SECY-02-0139. ${ }^{19}$ Of the seven issues, Issue 4: "To what extent should a probabilistic approach be used to establish the plant licensing basis?" specifically relates to the safety classification of SSCs. In the Staff Requirements Memorandum on SECY-03-0047, ${ }^{20}$ the Commission approved the staff's recommendation to allow a probabilistic approach for the safety classification of SSCs.

The NRC findings in the collective reviews for the DOE MHTGR and the Exelon PBMR licensing approaches and regulatory guidance have been taken into account in the formulation of the NGNP approach that is described in Section 3.

\subsubsection{PBMR Responses to NRC Requests for Additional Information}

This paper on SSC safety classification draws from the Pebble Bed Modular Reactor (Proprietary) Limited (PBMR) pre-application white paper of the same name but has been tailored to today's regulatory approaches, guidance and positions to form the NGNP approach. This PBMR white paper was submitted to the NRC on August 28,2006. ${ }^{21}$ In its letter of September 24, 2007, ${ }^{22} \mathrm{NRC}$ sent requests for additional information (RAI) on white papers that had been submitted by PBMR to NRC for review, including the SSC Classification white paper. Responses to these RAIs were provided by PBMR on March 21, $2008 .^{23}$ Subsequent to the provision of responses to the RAIs, the PBMR licensing project activities were discontinued, and the RAI responses were not reviewed by NRC. 


\subsection{Regulatory Basis Summary}

The NGNP Project has adopted the $10 \mathrm{CFR} 52^{26} \mathrm{COL}$ application process, as recommended in the Report to Congress, ${ }^{24}$ as the foundation for the NGNP licensing strategy.

As provided by $10 \mathrm{CFR} \S 52.81,{ }^{7}$ license applications will be reviewed by NRC for compliance with the standards set out in 10 CFR $20,{ }^{9} 50^{7}$ and its Appendixes, $51,{ }^{25} 73,{ }^{27}$ and $100 .{ }^{10}$ For safety classification of SSCs, various requirements of 10 CFR $20,{ }^{9} 50,{ }^{7}$ and $100^{10}$ apply but may, in some instances, require modification to be adaptable to HTGR technology.

The regulations promulgated under 10 CFR $20^{9}$ establish standards for protection of individual occupational workers and members of the public against ionizing radiation resulting from activities conducted under licenses issued by NRC to limits as prescribed by 10 CFR $20^{9}$ that may result from AOOs. For plant features (SSCs) designed to prevent or mitigate AOOs that may result in a radiation dose in excess of 10 CFR $20^{9}$ limits, safety classification and commensurate application of quality requirements are considered based upon risk significance of the event.

SSCs for reactors are primarily classified into one of two categories: 1) safety-related; or 2) nonsafety-related. 10 CFR $\$ 50.2^{7}$ defines safety-related SSCs as:

...those structures, systems and components that are relied upon to remain functional during and following design basis events to assure:

(1) The integrity of the reactor coolant pressure boundary;

(2) The capability to shut down the reactor and maintain it in a safe shutdown condition; or

(3) The capability to prevent or mitigate the consequences of accidents which could result in potential offsite exposures comparable to the applicable guideline exposures set forth in $\S 50.34(a)(1)$ or $\S 100.11$ of this chapter, as applicable.

Non-safety related SSCs are those which are not classified as safety-related.

SRP 3.2.2 $2^{6}$ describes an acceptable deterministic approach to classify fluid systems important to safety based upon the definitions provided in 10 CFR $\$ 50.2^{7}$ and identify their applicable construction codes and standards depending on the system or component function and relative importance to safety.

The optional safety classification of 10 CFR $§ 50.69$, "Risk-informed categorization and treatment of structures, systems and components for nuclear power reactors," for SSCs based on combinations of safety classification and risk significance as determined in a PRA. This alternative regulatory framework is further discussed in RG $1.201,{ }^{11}$ SECY-93-087, ${ }^{29}$ SECY-94$084,{ }^{30}$ and SECY-95-132. ${ }^{31}$

Included within Part 50 is $\$ 50.34^{7}$ which addresses the treatment of plant design features with respect to prevention and mitigation of design basis accidents and the limits of radiation dose exposure that may result from accidents The regulation prescribes an analytical approach for determining release of radiation and subsequent offsite exposure which were developed based on LWR technology. In addition, 10 CFR $\S 100.21(\mathrm{c})(2),{ }^{10}$ Non-Seismic Site Criteria, requires that the dose consequences of postulated accidents shall meet the criteria set forth in $\S 50.34(\mathrm{a})(1)^{7}$

The GDC of 10 CFR 50, Appendix A, establishes minimum requirements for the principal design criteria for water-cooled nuclear power plants. The GDC is also considered to be generally applicable to 
other types of nuclear power units and are intended to provide guidance in establishing the principal design criteria for such other units.

The NRC policy statement on the Regulation of Advanced Reactors set forth the NRC expectation that advanced reactor designs provide at least the same degree of protection of the environment, public health and safety, and common defense and security that is required for current generation light water reactors (LWR). In addition, NRC expects that advanced reactors will provide enhanced margins of safety or use simplified, inherent, passive, or other innovative means to accomplish their safety and security functions.

As noted in SECY-10-0034, ${ }^{5} \mathrm{NRC}$ expects to apply an approach to safety classification of SSCs that places more emphasis on the use of risk insights that are complemented by deterministic evaluations and engineering judgment. If necessary, special treatment requirements would be established to ensure required performance capability and reliability of safety significant SSCs using deterministic engineering judgment, complemented by insights from the design-specific PRA. The process described in this white paper is consistent with NRC's expectation presented in SECY-10-0034 and Option 2 described in the NGNP Licensing Strategy Report to Congress. ${ }^{24}$ 


\section{NGNP APPROACH TO STRUCTURES, SYSTEMS, and COMPONENTS SAFETY CLASSIFICATION}

This section describes the NGNP systematic approach to SSC safety classification. Section 3.1 states the purpose for classifying SSCs. Section 3.2 defines the safety classification categories. Section 3.3 describes the relationship to the other elements of the licensing approach. Section 3.4 discusses the safety classification process. Section 3.5 enumerates the classification process with examples. Finally, Section 3.6 addresses the approach to special treatment requirements.

\subsection{Purpose of Classifications and Safety Functions}

SCCs are classified relative to their safety significance to focus attention and resources on their design, construction, and operation commensurate with their safety significance.

\subsection{NGNP SSC Classification Categories}

The NGNP proposes the use of three primary safety classification categories as presented in section 1.5. These classification categories are Safety-Related and Non-Safety-Related. Non-Safety-Related SSCs is further classified according to the need to apply special treatments commensurate with their safety significance.

\subsection{Licensing Basis Events}

The NGNP Project white paper "NGNP Licensing Basis Event Selection"" discusses the selection of the LBEs. The process begins with identification of TLRC that are generic, quantitative measures of acceptable consequences or risks derived from NRC regulations. Within this process event sequences are binned into three frequency regions:

- Event sequences expected to occur within a plant lifetime are classified as AOOs

- Event sequences not expected to occur within a plant lifetime, but which might occur within the lifetime of a fleet of plants, are classified as DBEs

- Rare events sequences with frequencies lower than DBEs are classified as BDBEs.

Using LBEs, event sequences expressed in terms of frequencies and consequences are compared to the TLRC. Depending on the frequency region, SSCs performing safety functions required to ensure meeting the TLRC are classified as safety-related or non-safety-related with special treatment.

Section 3.4.2 discusses the classification of SSCs as safety-related based on LBEs. Section 3.4.3 discusses the determination of when a non-safety-related SSC provides significant DID, is subject to the application of Special Treatments, and is classified as NSRST.

\subsection{Proposed Safety Classification Process}

Safety classification of SSCs is made in the context of specific safety functions performed by the $\mathrm{SSC}$. The safety classification process is comprised of both deterministic engineering judgment and risk informed analyses and requires specification of special treatments to ensure that the SSC has the capability and reliability, given the environment and conditions under which the SSCs must be available, to perform its safety function. 


\subsubsection{Basis for Risk Informing the Criteria for Safety Classification}

Risk informing the safety classification of SSCs provides adequate protection of public health and safety by ensuring that the frequency and consequences of the accident event sequences (LBEs) meet the TLRC. As discussed in the LBE white paper, the LBE frequencies are a function of the frequencies of initiating events from internal events, internal and external hazards, and the reliabilities and capabilities of the SSCs (including the operator) to prevent an initiating event from progressing to an accident, to mitigate the consequences of an accident, or both to prevent the former and mitigate the latter. In some cases, the initiating events are failures of SSCs themselves, in which case the reliability of the SSC in the prevention of the initiating event needs to be considered. In other cases, the initiating events may represent challenges to the SSC in question, in which case the reliability of the SSC to perform a safety function in response to the initiating event needs to be considered. Finally, there are other cases in which the challenge to the SSC in question is defined by the combination of an initiating event and combinations of successes and failures of other SSCs in response to the initiating event.

\subsubsection{Classification of SSCs as Safety-Related}

The definition of safety-related includes application of deterministic engineering judgment and risk informed elements. Included within the application of engineering judgment is classification of the HTGR fuel which serves as the primary boundary relied upon to prevent the release of radionuclides. Also included is the classification of a set of SSCs provided to ensure safe shutdown of the reactor.

Risk-informed application of the safety classification process is applicable to SSCs of a facility or process that are relied upon to prevent or mitigate the consequences of accidents (LBEs) which could result in potential significant offsite exposures.

Safety-related SSCs that are relied on to perform a safety function necessary to safely shutdown the reactor and prevent or mitigate the consequences of accidents which could result in potential significant offsite exposures include:

- $\quad$ SSCs relied on to perform required safety functions to prevent or mitigate the consequences of DBEs to comply with the TLRC

- SSCs relied on to perform required safety functions to prevent the frequency of BDBEs with consequences greater than the 10 CFR $50.34^{7}$ dose limits from increasing into the DBE region.

The first step in the process of classifying SSCs as safety-related is to determine the required safety functions for DBEs. The required safety functions are the functions that need to be performed during DBEs to meet the TLRC. The next step for each required safety function is to examine the DBEs to determine which SSCs are available and have sufficient capability and reliability to meet the safety function. From the matrix of SSCs available for each safety function and considering all DBEs, a set of SSCs is classified as safety-related for a given required safety function to assure that it is accomplished. Considerations in this classification include the alternative set of SSCs that will be most readily shown with appropriate special treatment to have the capability and reliability needed.

BDBE events are analyzed with all the plant SSCs considered realistically (i.e., presumed available in the PRA according to their reliability and availability following each initiating event). Since some BDBEs may have consequences above those for DBEs and still comply with the NRC Safety Goal Qualitative and Quantitative Health Objectives (QHOs), ${ }^{32}$ assurance should be provided that the frequency of high consequence BDBEs remains below the lower frequency of the DBE region. Any BDBEs with consequences above the DBE region's dose limits of 10 CFR $\$ 50.34^{7}$ are reviewed to determine which safety functions are required to prevent them from increasing in frequency into the DBE region where their consequences would be unacceptable. The SSCs available and sufficient to perform the functions 
that keep a high consequence BDBE frequency very low are identified and, if needed, are classified as safety-related.

\subsubsection{SSCs Classified as Non-Safety-Related with Special Treatment}

For the classification option of special treatment for non-safety-related SSCs, NGNP anticipates application of non-safety-related but with special treatment requirements as follows:

- For SSCs relied on to perform safety functions to mitigate the consequences of AOOs to comply with the TLRC

- For SSCs relied on to perform safety functions to prevent the frequency of DBEs with consequences greater than the 10 CFR $20^{9}$ offsite dose limits from increasing into the AOO region.

Since, by definition, AOOs are expected to occur in the plant lifetime, operational measures will be implemented to assure that the TLRC are not exceeded for these events. In an analogous fashion to the mitigation of DBEs, the functions that are needed to meet the TLRC for AOO events are determined from a review of the PRA. The SSCs available to perform each of these safety functions are reviewed to select a set to receive greater attention from a risk, safety margin, and defense-in-depth perspective and are classified as NSRST. These SSCs are subject to the special treatment options discussed in Section 3.6.2.

Since DBEs can have consequences above those acceptable for AOOs, assurance must be provided that the frequency of those events with consequences greater than the 10 CFR $20^{9}$ dose limits for the AOO region is lower than the cut off for AOO events. SSCs performing this prevention safety function (i.e., SSCs whose successful operation would prevent the event sequence from being in the AOO region) are candidates for classification as NSRST. The first step in the process is to identify DBEs with consequences higher than the 10 CFR $20^{9}$ dose limits. The next step is to determine the prevention safety functions for these higher consequence DBEs. The final step is to select a set(s) of SSCs that will receive special treatment that perform each of those functions.

\subsection{Example NGNP Safety Classifications for SSCs Identified via Risk Informed Approach}

As discussed in Section 3.4, SSCs are required to perform a function in response to LBEs in one or more of the regions of the frequency-consequence chart. This performance function is applicable to LBEs in which the SSC mitigates the consequences of the challenge, as well as those in which its reliability helps to reduce the LBE frequency and higher consequences LBEs. Generic examples corresponding to SSCs providing functions resulting in SSC safety classification as safety-related, non-safety-related with special treatment, and non-safety-related, are shown in Figure 1 (below). 


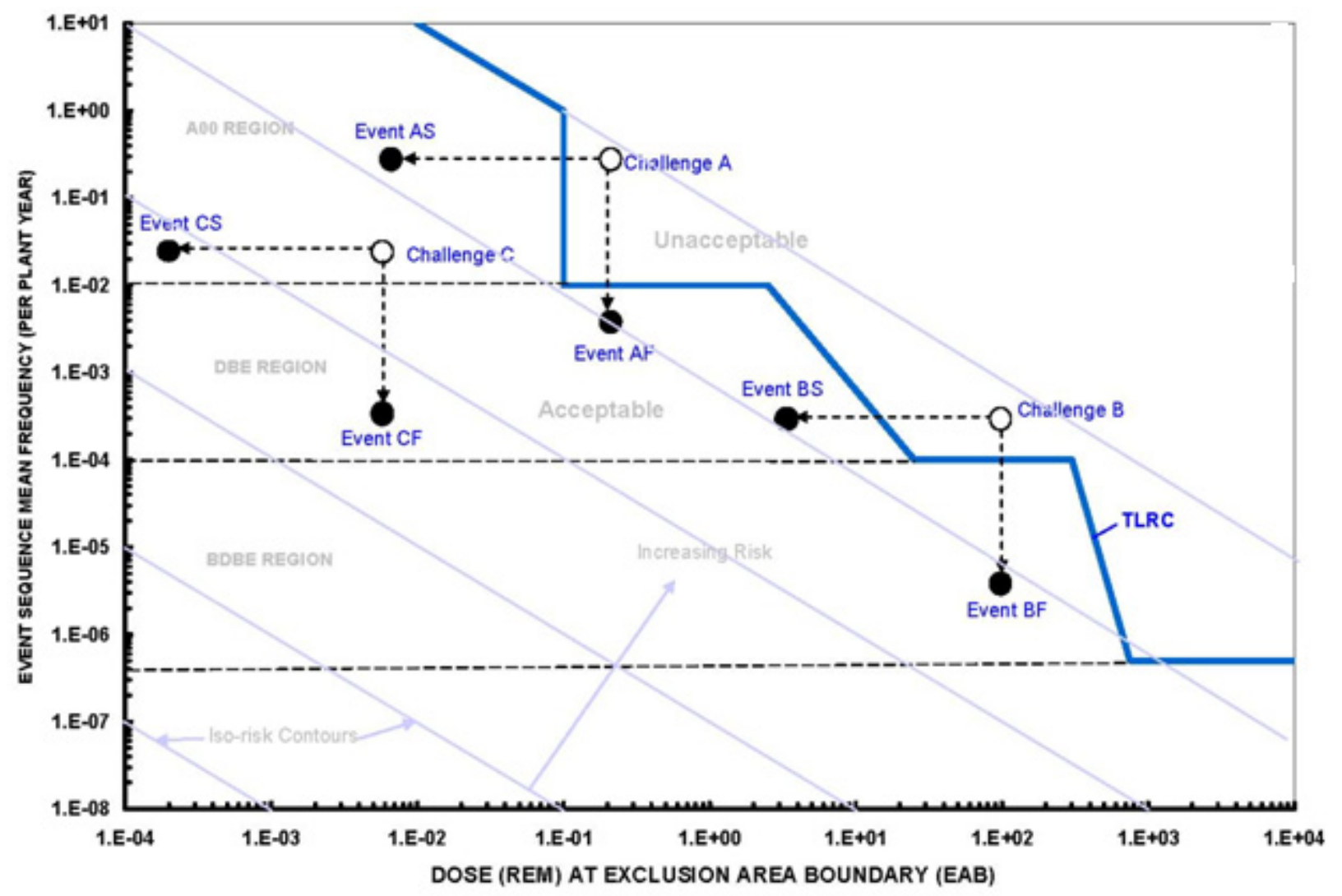

Figure 1. Impact of safety classified SSCs in prevention and mitigation of LBEs.

SSC AS is an example of an SSC whose successful performance mitigates (ensures) the consequences of an Event AS and remains below the TLRC thus preventing AOO (Challenge A); SSC AF is an example of an SSC whose successful performance prevents the frequency of a corresponding DBE (Event $\mathrm{AF}$ ), whose consequences exceed the AOO dose criteria, from moving into the AOO region. These SSCs would be classified as NSRST. Special treatment applied to this category of SSC helps to control the corresponding LBEs (AS and AF) within their respective LBE categories. An assumed degradation in performance of SSC $A_{S}$ with respect to its mitigation capability would result in the frequency and dose of event AS approaching that of Challenge A. An assumed degradation in the reliability of SSC AF would also result in the frequency and dose of event AF approaching that of Challenge A.

By varying the $\mathrm{LBE}$ frequency along the path from point $\mathrm{AF}$ to challenge $\mathrm{A}$, one may simulate degradation of the SSC(s) in comparison to what was predicted in the PRA, or one may investigate the impact of uncertainties in the assumed reliabilities of the SSCs. Hence, special treatment measures may not only change the locations of the LBEs on the frequency-dose plot, but also may reduce the uncertainty on the associated frequencies and doses.

SSC B(F,S) shows a similar behavior through the relationships among Events BS, BF, and challenge B for a safety-related SSC. SSC B(F,S) is classified as safety-related because its mitigation capability is necessary to keep the doses of DBEs within the limits specified in 10 CFR $\$ 50.34,{ }^{7}$ or its reliability is necessary to prevent the high consequence BDBE from moving into the DBE region where its consequences would be unacceptable.

SSC C(F,S) is an example of an SSC that is classified as non-safety-related because its corresponding LBEs are within the TLRC even when severe degradation of its performance is assumed. 


\subsection{Special Treatment for SSCs}

The purpose of special treatment requirements is twofold. First, special treatment ensures that the reliability and capability of each safety-related SSC are adequate for the prevention and mitigation of LBEs. The reliability and capability requirements of safety-related SSCs are derived from the frequencies and consequences of the LBEs that correspond to the SSCs in relation to the TLRC. Second, special treatment requirements increase the confidence that the safety-related SSCs will perform their safety functions in light of uncertainties about the reliabilities and capabilities of these SSCs. Hence, special treatment requirements help ensure that the frequencies and consequences of the LBEs fall within the TLRC as well as reduce the uncertainties about SSC reliability and performance in the context of the safety functions they perform in preventing and mitigating LBEs. The purpose of the special treatment is to increase the level of assurance that the SSCs will perform as predicted in the PRA under expected LBE conditions with the assessed uncertainties. As such, the special treatment requirements are an important element of defense-in-depth.

Section 3.6.1 addresses the application of special treatment to safety-related SSCs and Section 3.6.2 addresses the application of special treatment to non-safety-related with special treatment category.

\subsubsection{Special Treatment for Safety-Related SSCs}

The special treatment for the safety-related SSCs is commensurate with that needed for the SSCs to achieve their capability and reliability requirements during DBEs to meet the TLRC. Capability requirements are derived from accident mitigation considerations, whereas reliability requirements are derived from accident prevention considerations as illustrated with the examples of the previous section. Special treatment measures for this category focus on both the capability of SSCs to mitigate DBEs and the reliability of SSCs to prevent high consequence BDBEs. These measures begin by establishing the capabilities of the SSCs that are credited in the PRA with successful performance of safety functions during DBEs and the reliability requirements that are needed to prevent high consequence BDBEs. The elements of the special treatment requirements for safety-related SSCs are listed in Table 1. These include the elements of special treatment that are included in 10 CFR $50^{7}$ for safety-related SSCs in currently licensed reactors.

Since the HTGR safety design approach places emphasis on retention of radionuclides within the fuel during normal operation and all LBEs, it is anticipated that the full spectrum of special treatment will be employed in the design, manufacture, and operation of the fuel. Operational monitoring will be of particular importance.

Further, since the HTGR safety design relies on inherent characteristics of primarily passive components and structures to perform the required safety functions to retain the radionuclides in the fuel, special treatment measures appropriate and effective for passive components will be employed.

\subsubsection{NSRST SSCs}

The special treatment for the non-safety-related with special treatment category of SSCs is also commensurate with that needed for the SSCs to perform their capability and reliability requirements during AOOs. As previously noted, the LBEs for this category of SSCs are inherently more frequent and pose less severe challenges on the SSC than those for the safety-related category. Importantly, SSCs in this category do not have to perform required safety functions during DBEs in order to meet the 10 CFR $\S 50.34^{7}$ dose limits, whereas the safety-related SSCs are relied on to meet this requirement. Due to the high frequency of the events, the level of uncertainty in predicting the SSC performance and reliability is also less than for the safety-related SSCs. Hence, the special treatment requirements are more modest. In addition, the degree of reliability required of these SSCs is less than is the case with safety-related SSCs. 
Hence, the special treatment that is needed to provide the necessary reliability and capability is less than is the case with the safety-related category.

The elements of the special treatment measures for this category of SSCs are presented for comparison with the corresponding elements for the safety-related category in Table 1. As with the safety-related category of SSCs, this category begins by defining the capabilities and reliabilities of the SSCs that are needed to enforce the design and reliability assumptions in the PRA and to meet the TLRC as discussed in the previous section. Note that even when an element of special treatment is applied to NSRST classified SSCs, the specific requirements refer to a different set of LBEs to prevent and to mitigate in comparison with the safety-related category, and hence the specific requirements will be different.

Referring back to the example SSCs and their associated LBEs in Figure 1, it should be noted that special treatment measures in Table 1 include those that determine the location of the points on the frequency-dose plot, and also reduce the uncertainties associated with the LBE frequencies and doses. Hence, the process of assigning SSCs to safety classes and defining special treatment requirements is not only a function of the PRA results, but also a function of the uncertainties in the PRA results and the underlying models and assumptions. In some cases, special treatment may be applied to implement assumptions made in the PRA about the characteristics of SSCs that are modeled as well as those that may be screened out due to a low frequency of occurrence.

Note that the SSCs in this category serve a role of preventing DBEs, and hence of preventing challenges to the safety-related SSCs. The special treatment requirements for the safety-related SSCs are defined in a manner so as to be both necessary and sufficient to ensure that the consequences of DBEs are adequately mitigated and that any BDBEs with potentially high consequences are adequately prevented. When special treatment is applied to the NSRST classified SSCs, such treatment applies an additional element of prevention for these same DBEs and BDBEs. The safety classification and the approach to defining special treatment measures provide an important element of defense-in-depth by strengthening the strategies of accident prevention and mitigation. 
Table 1. Elements of special treatment for safety-related and non-safety-related with special treatment SSCs.

\begin{tabular}{|c|c|c|}
\hline Special treatment requirements & $\begin{array}{l}\text { Safety-related } \\
\text { SSCs }\end{array}$ & $\begin{array}{c}\text { Nonsafety-related } \\
\text { with special } \\
\text { treatment SSCs }\end{array}$ \\
\hline $\begin{array}{l}\text { Design requirements for SSC capabilities to mitigate specific } \\
\text { LBE challenges }\end{array}$ & $\sqrt{ }$ & $\sqrt{ }$ \\
\hline $\begin{array}{l}\text { Numerical targets for SSC reliability and availability to perform } \\
\text { safety functions }\end{array}$ & $\sqrt{ }$ & $\sqrt{ }$ \\
\hline Design requirements for independence, redundancy, and diversity & $\sqrt{ }$ & \\
\hline Design requirements for safety margins and design conservatism & $\sqrt{ }$ & \\
\hline $\begin{array}{l}\text { Codes and Standards for design, material procurement, } \\
\text { fabrication, construction, and operation }\end{array}$ & $\sqrt{ }$ & \\
\hline Seismic design basis & $\sqrt{ }$ & $\sqrt{ }$ \\
\hline Seismic qualification testing & $\sqrt{ }$ & \\
\hline Equipment qualification testing & $\sqrt{ }$ & \\
\hline Quality assurance and quality control & $\sqrt{ }$ & $\sqrt{ }$ \\
\hline Operational performance monitoring & $\sqrt{ }$ & $\sqrt{ }$ \\
\hline Operational controls & $\sqrt{ }$ & $\sqrt{ }$ \\
\hline Technical specifications & $\sqrt{ }$ & \\
\hline Materials surveillance testing & $\sqrt{ }$ & \\
\hline Pre-service and in-service inspection & $\sqrt{ }$ & $\sqrt{ }$ \\
\hline Pre-service and in-service testing & $\sqrt{ }$ & \\
\hline
\end{tabular}

$\sqrt{ }$ Indicates a level of special treatment for safety-related SSCs or consideration of the need for special treatment for NSRST. 


\section{ISSUES FOR RESOLUTION}

\subsection{NRC Discussion Topics}

Section 1.4 introduced a set of issues to be addressed in this white paper. These issues are framed in terms of the following questions regarding the safety classification of SSCs to support the NGNP COL Application:

1. What is the role of safety classification of SSCs in the risk-informed performance-based licensing approach for the NGNP? (See Section 3.4.1.)

2. What is an appropriate, systematic, and reproducible approach for safety classification of SSCs in a risk-informed, performance-based licensing approach? (See Sections 3.4.2 and 3.5.)

3. What are appropriate safety class categories for SSCs? (See Section 3.2.)

4. How are deterministic and probabilistic approaches used and integrated into the safety classification process? (See Section 3.4.2.)

5. What is the approach for assigning special treatment to assure the required degree of reliability and capability for SSCs classified as safety-related? (See Sections 3.4.2, 3.6, and 3.6.1.)

6. What is the approach for assigning special treatment to assure the required degree of reliability and capability for SSCs classified as non-safety-related with special treatment? (See Sections 3.4.3, 3.6, and 3.6.2.)

\subsection{Outcome Objectives}

The objective of this paper is to solicit NRC feedback and agreement on SSC safety classification sufficient to support NGNP licensing including relevant elements of a nuclear plant life cycle. Specifically, feedback is requested regarding NRC agreement with the following statements, or that the NRC provide an alternate set of statements that would be acceptable:

1. The NGNP approach to risk-informed safety classification and special treatment that blends the strengths of probabilistic and deterministic methods is acceptable

2. The NGNP risk-informed safety classification categories and the bases for SSC classification within each category are acceptable

3. The special treatment for the SR category of classification is commensurate with ensuring the SSCs ability to perform their safety function for DBEs and high consequence BDBEs

4. The special treatment for the NSRST category is commensurate with ensuring the SSCs ability to perform their safety function of providing significant DID. 


\section{REFERENCES}

1. INL, 2010, NGNP Licensing Basis Event Selection, INL/EXT-10-19521, September 2010.

2. INL, 2009, NGNP Defense in Depth Approach, INL/EXT-09-17139, December 2009.

3. 60 FR 42622, 1995, "Use of Probabilistic Risk Assessment Methods in Nuclear Regulatory Activities; Final Policy Statement,” U.S. Nuclear Regulatory Commission, August 16, 1995.

4. SECY-03-0047, 2003, "Policy Issues Related to Licensing Non-Light-Water Reactor Design," U.S. Nuclear Regulatory Commission, Issue 4, March 28, 2003.

5. SECY-10-0034, 2010, "Potential Policy, Licensing, and Key Technical Issues for Small Modular Nuclear Reactor Designs," U.S. Nuclear Regulatory Commission, March 28, 2010.

6. SRP 3.2.2, 1989, "System Quality Group Classification, NUREG-0800, Nuclear Regulatory Commission, 1989.

7. 10 CFR 50, "Domestic Licensing of Production and Utilization Facilities," U.S. Nuclear Regulatory Commission.

8. RG 1.26, 2007, "Quality Group Classifications and Standards for Water-, Steam-, and RadioactiveWaste-Containing Components of Nuclear Power Plants," U.S. Nuclear Regulatory Commission, Revision 4, March 2007.

9. 10 CFR 20, "Standards for Protection against Radiation," U.S. Nuclear Regulatory Commission.

10. 10 CFR 100, "Reactor Site Criteria,” U.S. Nuclear Regulatory Commission.

11. RG 1.201, 2004, "Guidelines for Categorizing Structures, Systems, and Components in Nuclear Power Plants According to their Safety Significance," U.S. Nuclear Regulatory Commission.

12. 73 FR 60612, 2008, "Regulation of Advanced Reactors," Final Policy Statement, U.S. Nuclear Regulatory Commission, October 14, 2008.

13. ASME III, 2008, "Nuclear Power Plant Components," ASME III, Boiler and Pressure Code, 2008.

14. INL, 2010, "NGNP Mechanistic Source Terms White Paper," INL/EXT -10-17997, Rev. 0, July 2010.

15. NUREG-1338, 1995, "Preapplication Safety Evaluation Report for the Modular High-Temperature Gas-Cooled Reactor (MHTGR)," Sections 4.2.5, 5.2.2 and 5.2.7, December 1995.

16. SECY-93-0092, 1993, "Issues Pertaining to the Advanced Reactor (PRISM, MHTGR, and PIUS) and Canadian Deuterium Uranium Reactor (CANDU) 3 Designs and Their Relationship to Current Regulatory Requirements," U.S. Nuclear Regulatory Commission, April 6, 1993 (Correction issued April 28, 1993).

17. NUREG-1338, "Preapplication Safety Evaluation Report for the Modular High-Temperature GasCooled Reactor (MHTGR)," December 1995.

18. U.S. Nuclear Regulatory Commission Letter, Subject: NRC Staff's Preliminary Findings Regarding Exelon Generation's (Exelon's) Proposed Licensing Approach For The Pebble Bed Modular Reactor (PBMR), March 26, 2002.

19. SECY-02-0139, 2002, "Plan for Resolving Policy Issues Related to Licensing Non-Light Water Reactor Designs,” U.S. Nuclear Regulatory Commission, July 22, 2002. 
20. SRM-03-0047, 2003, "Staff Requirements Memorandum for SECY-03-0047 - Policy Issues Related to Licensing Non-Light Water Reactor Designs," U.S. Nuclear Regulatory Commission, June 26, 2003.

21. Wallace, Edward G., 2006, "PBMR White Paper: SSC Classification,” U.S. Nuclear Regulatory Commission Document Control Desk, August 28, 2006.

22. U.S. Nuclear Regulatory Commission, 2007, "Requests For Additional Information Regarding Pebble Bed Modular Reactor (PBMR) Pre-Application White Papers," September 24, 2007.

23. Pebble Bed Modular Reactor, 2008, "Response to Requests for Additional Information," Limited to U.S. Nuclear Regulatory Commission, March 21, 2008.

24. INL, 2008, "NGNP Licensing Strategy Report to Congress," August 2008.

25. 10 CFR 51, 2010, "Environmental Protection Regulations for Domestic Licensing and Related Regulatory Functions,” U.S. Nuclear Regulatory Commission.

26. 10 CFR 52, 2010, "Licenses, Certifications, and Approvals for Nuclear Power Plants," U.S. Nuclear Regulatory Commission.

27. 10 CFR 73, 2010, "Physical Protection of Plants and Materials," U.S. Nuclear Regulatory Commission.

28. 40 CFR 190, 2010, "Environmental Radiation Protection Standards for Nuclear Power Operations," Environmental Protection Agency.

29. SECY-93-087, 1993, "Policy, Technical and Licensing Issues Pertaining to Evolutionary and Advanced Light-Water Reactor (ALWR) Designs,” U.S. Nuclear Regulatory Commission, April 2, 1993.

30. SECY-94-084, 1994, "Policy and Technical Issues Associated with the Regulatory Treatment of NonSafety Systems,” U.S. Nuclear Regulatory Commission, June 30, 1994.

31. SECY-95-132, 1995, "Policy and Technical Issues Associated with the Regulatory Treatment of NonSafety Systems (RTNSS) in Passive Plant Designs," U.S. Nuclear Regulatory Commission, June 28, 1995.

32. 51 FR 28044, 1986, "Safety Goals for the Operations of Nuclear Power Plants; Policy Statement," U.S. Nuclear Regulatory Commission, August 21, 1986.

33. RG 1.29, 2007, "Seismic Design Classification,” U.S. Nuclear Regulatory Commission, Revision 4, March 2007.

34. RG 1.117, 1978, “Tornado Design Classification,” U.S. Nuclear Regulatory Commission, Revision 1, April 1978.

35. RG 1.143, 2001, "Design Guidance for Radioactive Waste Management Systems, Structures, and Components Installed in Light-Water-Cooled Nuclear Power Plants," U.S. Nuclear Regulatory Commission, Revision 2, November 2001. 
Appendix A

NRC Regulations 


\section{Appendix A NRC Regulations}

As noted in section 2.1 of this white paper, NRC has promulgated regulations that are directed at developing safety classifications for structures, systems, and components. These regulatory requirements were developed based on LWR technology, and their adaptation to HTGR technology may require reevaluation. The regulations of concern are 10 CFR 20, ${ }^{9} 50^{7}$ and Appendix A, and $100 .{ }^{10}$

\section{CFR 20, Standards for Protection Against Radiation}

The regulations promulgated under 10 CFR Part $20^{9}$ establish standards for protection against ionizing radiation resulting from activities conducted under licenses issued by the NRC. It is the purpose of the regulations in this part to control the receipt, possession, use, transfer, and disposal of licensed material by any licensee in such a manner that the total dose to an individual occupational worker or member of the public does not exceed the standards for protection against radiation prescribed in the regulations in this part. Plant design and operation shall include features to control the occupational dose to individuals to be as low as reasonably achievable and in no case exceed the limits described in 10 CFR $\S 20.1201^{9}$ and $\$ 20.1207^{9}$ for occupational dose. Dose limits from plant operation for individual members of the public are described in 10 CFR $\$ 20.1301^{9}$. In addition to the requirements of this part, compliance with the provisions of EPA's generally applicable environmental radiation standards in 40 CFR Part $190^{28}$ shall apply as described in 10 CFR $\$ 20.1301(\mathrm{e}) .{ }^{9}$ Event sequences expected to occur within the NGNP plant lifetime, considering multiple reactor modules, are classified as anticipated operational occurrences (AOOs). AOOs are evaluated against the dose limits of 10 CFR Part $20 .{ }^{9}$ For plant features (SSCs) designed to prevent or mitigate AOOs that may result radiation dose in excess of Part $20^{9}$ limits, safety classification and commensurate application of quality requirements are considered based upon risk significance of the event.

\section{CFR 50, Domestic Licensing of Production and Utilization Facilities and Appendix A, General Design Criteria ${ }^{7}$}

\section{CFR 100, Reactor Site Criteria ${ }^{10}$}

The regulations promulgated under 10 CFR Part $50^{7}$ provide the framework and requirements for licensing and production facilities. Although these regulations were developed for specific application to LWR technologies, they contain certain precepts and principles generally adaptable to HTGR technology.

Included within Part 50 is $\$ 50.34^{7}$ which addresses the treatment of plant design features with respect to prevention and mitigation of design basis accidents and the limits of radiation dose exposure that may result from accidents. Event sequences not expected to occur within a plant lifetime, but which might occur within a fleet of plants, are classified as design basis events (DBEs). DBEs are conservatively evaluated against the dose limits of $10 \mathrm{CFR} \S 50.34^{7}$ to the extent practicable. The regulation prescribes an analytical approach for determining release of radiation and subsequent offsite exposure which are developed based on LWR technology. The prescribed analytical approach as described in $\S 50.34(\mathrm{a})(1)(\mathrm{D})^{7}$ and $\S 52.79(\mathrm{a})(1)^{26}$ may require reevaluation due to the unique and passive features of the NGNP to prevent and mitigate DBEs. SSCs which provide DBE prevention and mitigation features will be classified to the extent practicable in accordance with the guidance of RG $1.26^{8}$ or alternately in accordance with RG 1.26 in conjunction with $10 \mathrm{CFR} \S 50.69^{7}$ according to their risk significance.

Under the provisions of $\S 50.34(a)(1){ }^{7}$ an application for a construction permit must include the principal design criteria for a proposed facility. These design criteria are presented in Appendix A to 10 CFR $50{ }^{7}$ The principal design criteria establish the necessary design, fabrication, construction, testing, 
and performance requirements for structures, systems, and components important to safety; that is, structures, systems, and components that provide reasonable assurance that the facility can be operated without undue risk to the health and safety of the public. In addition, 10 CFR $\$ 100.21(\mathrm{c})(2),{ }^{10}$ NonSeismic Site Criteria, requires that the dose consequences of postulated accidents shall meet the criteria set forth in $\S 50.34(\mathrm{a})(1)$.

The General Design Criteria (GDC) of 10 CFR 50, Appendix A, establish minimum requirements for the principal design criteria for water-cooled nuclear power plants similar in design and location to plants for which construction permits have been issued by the Commission. The GDC are also considered to be generally applicable to other types of nuclear power units and are intended to provide guidance in establishing the principal design criteria for such other units.

SSCs which provide an accident prevention and mitigation function are expected to conform to GDC 1,2 , and 60 as referenced in RG $1.29,{ }^{33} 1.117,{ }^{34}$ and $1.143,{ }^{35}$ which are generally applicable to HTGR technology, but in some cases may require reevaluation for consideration of HTGR technology.

GDC 1 states:

Structures, systems, and components important to safety shall be designed, fabricated, erected, and tested to quality standards commensurate with the importance of the safety functions to be performed. Where generally recognized codes and standards are used, they shall be identified and evaluated to determine their applicability, adequacy, and sufficiency and shall be supplemented or modified as necessary to assure a quality product in keeping with the required safety function.

The quality standards applied to SSCs are anticipated to be based on the risk significance of the accident prevention and mitigation function performed. In addition, due to the unique nature of some NGNP SSCs, additional code development work will be necessary.

GDC 2 states:

Structures, systems, and components important to safety shall be designed to withstand the effects of natural phenomena such as earthquakes, tornadoes, hurricanes, floods, tsunami, and seiches without loss of capability to perform their safety functions. The design bases for these structures, systems, and components shall reflect: (1) Appropriate consideration of the most severe of the natural phenomena that have been historically reported for the site and surrounding area, with sufficient margin for the limited accuracy, quantity, and period of time in which the historical data have been accumulated, (2) appropriate combinations of the effects of normal and accident conditions with the effects of the natural phenomena and (3) the importance of the safety functions to be performed.

Design of SSCs to withstand the effects of natural phenomena is expected to conform to GDC 2 based on the risk significance of the accident prevention and mitigation function performed.

GDC 60 states:

The nuclear power unit design includes means to suitably control the release of radioactive materials in gaseous and liquid effluents and to handle radioactive solid waste produced during normal reactor operation, including anticipated operational occurrences. The release of radioactive materials from external man-induced events and design basis accidents must also be controlled.

SSCs that may contain radioactive material are evaluated for the potential consequences of accidental releases and are classified based upon the risk significance of such releases. 